
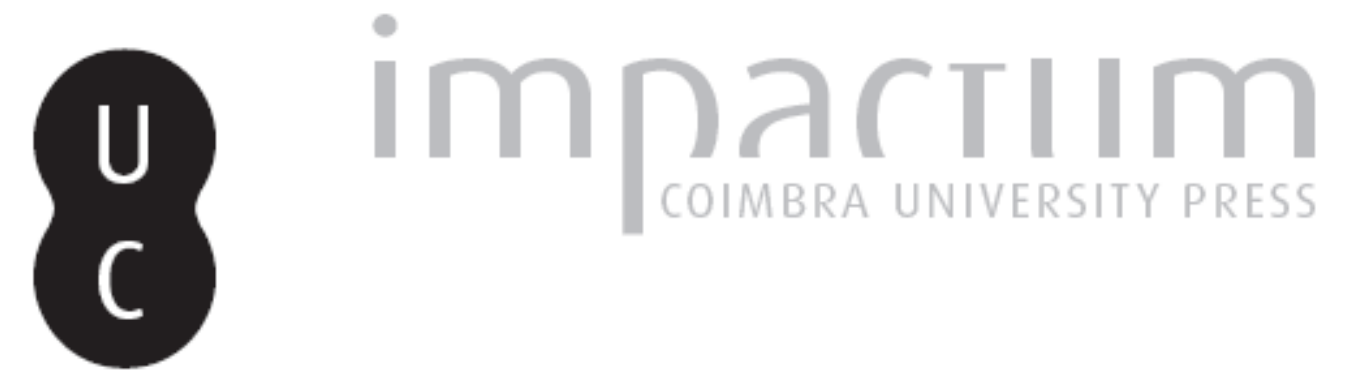

\title{
Três décadas de incêndios florestais em Portugal: incidência regional e principais fatores responsáveis
} \author{
$\begin{array}{ll}\text { Autor(es): } & \text { Nunes, Adélia; Lourenço, Luciano; Bento-Gonçalves, António; Vieira, } \\ \text { António } & \end{array}$
}
Publicado por: Faculdade de Letras da Universidade de Coimbra, Departamento de Geografia

URL persistente:

URI:http://hdl.handle.net/10316.2/30205

DOI: $\quad$ DOI:http://dx.doi.org/10.14195/0871-1623_32_10

Accessed : $\quad$ 26-Apr-2023 16:08:56

A navegação consulta e descarregamento dos títulos inseridos nas Bibliotecas Digitais UC Digitalis, UC Pombalina e UC Impactum, pressupõem a aceitação plena e sem reservas dos Termos e Condições de Uso destas Bibliotecas Digitais, disponíveis em https://digitalis.uc.pt/pt-pt/termos.

Conforme exposto nos referidos Termos e Condições de Uso, o descarregamento de títulos de acesso restrito requer uma licença válida de autorização devendo o utilizador aceder ao(s) documento(s) a partir de um endereço de IP da instituição detentora da supramencionada licença.

Ao utilizador é apenas permitido o descarregamento para uso pessoal, pelo que o emprego do(s) título(s) descarregado(s) para outro fim, designadamente comercial, carece de autorização do respetivo autor ou editor da obra.

Na medida em que todas as obras da UC Digitalis se encontram protegidas pelo Código do Direito de Autor e Direitos Conexos e demais legislação aplicável, toda a cópia, parcial ou total, deste documento, nos casos em que é legalmente admitida, deverá conter ou fazer-se acompanhar por este aviso.

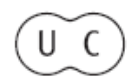




\title{
Três décadas de incêndios florestais em Portugal: incidência regional e principais fatores responsáveis
}

\author{
Adélia Nunes \\ Departamento de Geografia e Centro de Estudos em Geografia e Ordenamento do Território (CEGOT). Faculdade de Letras da Universidade de Coimbra.

\section{Luciano Lourenço} \\ Departamento de Geografia e Centro de Estudos em Geografia e Ordenamento do Território (CEGOT). Faculdade de Letras da Universidade de Coimbra.
}

\section{António Bento-Gonçalves}

Departamento de Geografia e Centro de Estudos em Geografia e Ordenamento do Território (CEGOT). Universidade do Minho.

\section{António Vieira}

Departamento de Geografia e Centro de Estudos em Geografia e Ordenamento do Território (CEGOT). Universidade do Minho.

\section{Resumo:}

Os incêndios florestais constituem, em Portugal continental, o mais relevante problema ambiental e, frequentemente, têm sido explicados pelas características climáticas e meteorológicas do nosso território, por estas afetarem tanto o desenvolvimento como a inflamabilidade dos combustíveis. Todavia, o perfil do clima português, mediterrâneo, não justifica, por si só, nem o elevado número de ignições, nem a vasta área ardida ao longo destas últimas três décadas. Com o presente trabalho, pretende-se avaliar a evolução e as tendências da distribuição regional, quer das ocorrências quer das áreas ardidas em Portugal continental, desde 1981 até 2010, bem como identificar inter-relações, ao nível do distrito, entre variáveis biofísicas, trajectórias sócio-demográficas e incidência de incêndios florestais.

Palavras-chave: Ignições. Área ardida. Variabilidade regional. Fatores responsáveis. Portugal.

\section{Résumé:}

Trois décennies d'incendies de forêt au Portugal: l'incidence régionale et les principaux facteurs responsables

Les feux de forêt au Portugal continental, sont le problème environnemental le plus important et ont souvent été expliquée par les caractéristiques climatiques et météorologiques de notre territoire, parce qu'ils affectent à la fois la disponibilité et l'inflammabilité des combustibles. Toutefois, le profil du climat portugais, méditerranéen, n'explique pas, à lui seul, ni le nombre élevé d'ignitions ni la vaste superficie brûlée au cours de ces trois dernières décennies. Le présent travail vise à évaluer les progrès et les tendances dans la répartition régionale des occurrences et les superficies brûlées du Portugal continental, de 1981 à 2010, et d'identifier les inter-relations au niveau du district, entre les variables biophysiques, les trajectoires socio-démographiques et l'incidence des incendies de forêt.

Mots-clés: Ignitions. Superficie brûlée. Variabilité régionale. Facteurs responsables. Portugal.

\section{Abstract:}

Three decades of forest fires in Portugal: regional incidence and main driving forces

Forest fires constitute, in Portugal mainland, the most relevant environmental problem and have been frequently explained by the climatic and meteorological characteristics of our territory, affecting both the availability and flammability of fuels. However, the Mediterranean profile of the Portuguese climate does not justify, per se, neither the high number of ignition nor the large burnt area over the last three decades. The purpose of this paper was to analyze the evolution and tendencies in regional distribution of both forest fire ignitions and burnt areas in mainland Portugal, since 1981 until 2010, and to identify the relationship between biophysical variables and socio-demographic trajectories and the incidence of forest fires at the district level.

Keywords: Ignitions. Burnt area. Regional variability. Main driving forces. Portugal. 
Introdução

Os incêndios florestais fazem parte integrante dos ecossistemas mediterrâneos, mas também representam, na atualidade, um dos seus principais fatores de degradação. Em Portugal continental, constituem o mais relevante problema ambiental e são frequentemente considerados a principal causa de degradação da camada edáfica superficial.

A nível europeu, os países da bacia do Mediterrâneo assinalaram, nestas últimas décadas, um importante incremento tanto no número de ocorrências como na área percorrida pelas chamas (JRC, 2005). Esta tendência crescente, apesar da irregularidade temporal no número de ocorrências e na área ardida, distingue Portugal dos restantes países do Sul da Europa, não apenas pelo elevado número de ignições, mas, sobretudo, devido à maior proporção de área ardida, em particular nas regiões Centro e Norte.

As condições climáticas e meteorológicas de um determinado espaço geográfico desempenham um papel crucial na ocorrência de incêndios, por afetarem tanto a quantidade como a inflamabilidade dos combustíveis (Rebelo, 1980; Lourenço, 1988, 1991; Pyne et al. 1996; SkINNER et al., 1999; VIEGAS e VIEGAS, 1994; KUnKEL, 2001; VIEGAS et al. 2001, 2004; Pereira et al. 2005; Carvalho et al., 2008; Westerling, 2008; Camia e Amatulli, 2009).

Em Portugal, são inúmeros os trabalhos em que se relacionam as características climáticas e meteorológicas do nosso território com a ocorrência dos incêndios (Rebelo, 1980; Lourenço, 1988 e 1991; Lourenço e Gonçalves, 1990; Viegas et al., 1992; Viegas e Viegas, 1994; Pereira et al. 2005; Carvalho et al., 2008). Todavia, o perfil do clima português, mediterrâneo, não justifica, por si só, nem o elevado número de ignições nem a vasta área ardida ao longo destas últimas três décadas. Com efeito, a nível regional, a incidência de incêndios florestais interrelaciona-se com um conjunto vasto de fatores, meteorológicos, mas também orográficos e ligados ao uso e cobertura vegetal do solo (Rothermel, 1983; Mermoz et al., 2005).

Com o presente trabalho pretende-se (1) analisar a evolução e a tendência quer do número de ocorrências quer das áreas ardidas em Portugal continental, desde 1981 até 2010, bem como a sua distribuição regional; (2) detetar inter-relações entre as variáveis biofísicas, as trajetórias sócio-demográficas e incidência de incêndios florestais, a nível de distrito, e, por último, (3) identificar e caracterizar os principais fatores responsáveis pelos incêndios florestais em Portugal continental.
Área de Estudo

Portugal Continental apresenta, apesar da sua modesta dimensão territorial, importantes contrastes físicos e recentes trajetórias sociodemográficas complexas, com reflexos muito significativos no uso e ocupação do solo. Assim, os quantitativos anuais de precipitação variam entre pouco mais de $500 \mathrm{~mm}$, em Faro, e cerca de 1500 mm, em Viana do Castelo (Quadro I), sabendo-se que estes valores são fortemente reforçados nas montanhas do NW e Centro de Portugal.

Também as trajetórias demográficas assinalam contrastes relevantes, menos pautadas pela dicotomia Norte/Sul, pois esta é mais determinada pela fisiografia do terreno e pelas características do clima, mas assinaladas, sobretudo, pela oposição entre o Litoral e o Interior. Embora com diferentes taxas e ritmos, é generalizada a perda de população nos distritos do interior, desde a segunda metade do século passado. Com a enorme saída de população destes distritos (Guarda, Beja, Portalegre, Bragança, Vila Real, Castelo Branco e Évora) reduziram-se as densidades populacionais e acelerou-se o processo de envelhecimento.

As alterações verificadas nos usos do solo e cobertura vegetal, em consequência do abandono agrícola, são antes de mais, o resultado da dinâmica da sua ocupação populacional (Almeida et al., 2009). A área agrícola, assente na cultura de cereais de sequeiro, dominava a paisagem em meados da década de 50 do passado século. A nível nacional ocupava $50 \%$ do território, com relevantes variações inter-regionais, salientandose os distritos de Bragança, Lisboa, Beja e Faro, com valores a rondar $70 \%$. As áreas florestal e inculta estendiam-se, respetivamente, por $23 \%$ e $15 \%$ do território continental.

A análise dos resultados obtidos a partir do Corine Land Cover, para 2006, mostra alterações muito expressivas, sobretudo ao nível das áreas agrícola e inculta. A primeira delas assinala uma perda de $66 \%$, enquanto que, a segunda, regista um incremento de $77 \%$. Por sua vez, a floresta manteve a sua expressão geográfica praticamente inalterável.

\section{Metodologia}

A divulgação dos dados relativos aos incêndios florestais é da responsabilidade da Autoridade Florestal Nacional, entidade que, até ao ano de 2006, também foi responsável pela recolha e tratamento dessa informação. Do conjunto de variáveis disponibilizadas, para 
Quadro I

Principais características dos 18 Distritos de Portugal Continental

\begin{tabular}{|c|c|c|c|c|c|c|c|c|c|c|c|}
\hline \multirow[b]{3}{*}{ Distritos } & \multirow{2}{*}{\multicolumn{2}{|c|}{$\begin{array}{c}\text { CLIMA } \\
(1971-2000) \\
\end{array}$}} & \multicolumn{3}{|c|}{ Demografia } & \multicolumn{6}{|c|}{ UsO DO SOLO/COBERTO VEGETAL } \\
\hline & & & \multirow{2}{*}{$\frac{(1960-2001)}{\mathrm{VP}}$} & \multicolumn{2}{|c|}{2001} & \multicolumn{3}{|c|}{ SROA $(1956 / 57)$} & \multicolumn{3}{|c|}{ CLC ( 2006) } \\
\hline & PMA & TMA & & DP & IE & AA & $\mathrm{AF}$ & $\mathrm{Al}$ & AA & $\mathrm{AF}$ & Al \\
\hline V. Castelo & 1470 & 14.8 & -8 & 112 & 97 & 28 & 30 & 38 & 3 & 21 & 47 \\
\hline Braga & 1466 & 14.5 & 63 & 329 & 46 & 37 & 34 & 27 & 4 & 27 & 32 \\
\hline Porto & 1254 & 14.7 & 78 & 781 & 53 & 40 & 45 & 11 & 5 & 27 & 16 \\
\hline Vila Real & 1074 & 13.3 & -31 & 51 & 96 & 38 & 33 & 37 & 19 & 14 & 43 \\
\hline Bragança & 758 & 12.3 & -34 & 23 & 129 & 71 & 7 & 18 & 23 & 9 & 33 \\
\hline Aveiro & 908 & 15.4 & 59 & 268 & 64 & 34 & 46 & 15 & 11 & 43 & 18 \\
\hline Viseu & 1170 & 13.6 & -19 & 79 & 89 & 39 & 34 & 25 & 11 & 28 & 35 \\
\hline Coimbra & 905 & 15.5 & 1 & 110 & 104 & 37 & 45 & 16 & 10 & 41 & 28 \\
\hline Guarda & 882 & 10.9 & -43 & 32 & 134 & 63 & 13 & 19 & 15 & 9 & 51 \\
\hline Leiria & 945 & 14.7 & 23 & 136 & 83 & 47 & 40 & 11 & 12 & 33 & 22 \\
\hline C. Branco & 758 & 15.7 & -35 & 31 & 142 & 54 & 22 & 13 & 16 & 24 & 40 \\
\hline Santarém & 697 & 16.0 & -2 & 66 & 108 & 55 & 27 & 5 & 20 & 34 & 20 \\
\hline Lisboa & 726 & 17.0 & 73 & 789 & 83 & 71 & 13 & 11 & 26 & 11 & 10 \\
\hline Portalegre & 852 & 15.2 & -39 & 20 & 144 & 56 & 4 & 3 & 33 & 25 & 13 \\
\hline Setúbal & 716 & 16.2 & 152 & 161 & 75 & 53 & 19 & 7 & 19 & 43 & 12 \\
\hline Évora & 609 & 15.9 & -22 & 23 & 120 & 54 & 2 & 1 & 36 & 23 & 6 \\
\hline Beja & 572 & 16.3 & -46 & 15 & 132 & 70 & 2 & 3 & 41 & 14 & 15 \\
\hline Faro & 509 & 17.4 & 29 & 85 & 96 & 71 & 11 & 13 & 9 & 14 & 42 \\
\hline Média & 904 & 15.0 & 11 & 172 & 100 & 51 & 23 & 15 & 17 & 24 & 27 \\
\hline
\end{tabular}

PMA: Precipitação média annual (em mm); TMA: Temperatura média annual (em $\left.{ }^{\circ} \mathrm{C}\right)$; VP: Variação na população residente (em \%); DP: Densidade populacional; IE: Índice de envelhecimento; AA: Área agrícola (em \%) (terras aráveis + culturas permanentes); AF: Área florestal (em \%); Al: Área inculta (em \%) (Comunidades de herbáceas e arbustivas + espaços abertos com escassa vegetação); SROA: Serviço de Reconhecimento e Ordenamento Agrário; CLC: CoRINE Land Cover.

o período de 1981-2010 (3 décadas), utilizaram-se apenas duas: número de ocorrências e área ardida, por distrito. Estas duas variáveis foram, posteriormente, interrelacionadas com a superfície total do distrito, permitindo a sua análise em termos tanto de números absolutos como de valores relativos.

Com o objetivo de determinar os fatores que, à escala regional, influenciam a ocorrência de incêndios florestais, foi definido um conjunto de variáveis (independentes), onde se integram as características físicas, as trajetórias sociodemográficas, as mudanças no uso do solo e coberto vegetal e, ainda, outras associadas à estrutura da propriedade (Quadro II).

Foi, ainda, determinado um indicador de rugosidade topográfica, para cada distrito, de acordo com o adaptado de Melton, proposto por Pereira e Ramos (1997), e que resulta da razão entre a amplitude altimétrica e a raiz quadrada da área do distrito. Foi utilizada, como documento de base, a Carta hipsométrica do Atlas do Ambiente, à escala de 1/1000000 (1982). As variáveis relativas ao clima, foram recolhidas do Instituto de Meteorologia, para as estações disponíveis, que coincidem com as sedes de distrito.

As variáveis sociodemográficas e as ligadas à estrutura da propriedade, foram extraídas dos documentos oficiais, disponibilizados pelo Instituto Nacional de Estatística, enquanto as relativas ao uso e coberto ve- getal do solo tiveram como fonte, para meados do século passado, o levantamento efetuado pelo SROA (Serviço de Reconhecimento e Ordenamento do Território) e, para 2006, o mapa CoRINE Land Cover, disponibilizado pela Agência Europeia do Ambiente.

Para detetar tendências (positivas, negativas ou nulas) no número de ocorrências e áreas ardidas, nas três décadas analisadas, aplicaram-se linhas de tendência/regressão, tendo-se optado por aquela que melhor se ajustava à distribuição (com o maior valor de $\mathrm{R}^{2}$ ).

Para avaliar o grau de correlação entre o conjunto de variáveis, dependentes e independentes, aplicouse o coeficiente $\rho$ de Spearman, teste não paramétrico (SNeYers, 1992; Yue et al., 2002). Este coeficiente não é sensível a assimetrias na distribuição, nem à presença de outliers, não exigindo, portanto, que os dados provenham de duas populações normais. 0 coeficiente $\rho$ de Spearman varia entre 1 e -1. Quanto mais próximo estiver destes extremos, maior será a associação, directa ou inversa, entre as variáveis.

Com o objetivo de testar dependências cumulativas de uma única variável dependente, em relação a diversas variáveis independentes, foi utilizada Regressão Linear Múltipla - regressão passo-a-passo" ou stepwise regression. A regressão linear múltipla, passo-apasso, permite a análise da relação entre uma variável dependente $(Y)$ e um conjunto de variáveis indepen- 
dentes ( $X^{\prime} s$ ), eliminando as que apresentam um elevado grau de colinearidade. Expressa-se através da seguinte fórmula:

$$
Y_{i}=B_{0}+B_{1} X_{1}+B_{2} X_{2}+\ldots B_{n} X_{n}+\varepsilon_{i}
$$

Em que $Y_{i}$ é o teor da variável dependente; $B_{0}$ é uma constante; $X_{1} . . X_{n}$ são as variáveis independentes $e$ $B_{1 \ldots} B_{n}$ os coeficientes ligados às variáveis $X_{1} X_{n}$, respetivamente calculados de forma a obter o melhor ajuste possível aos dados. $\varepsilon_{\mathrm{i}}$ corresponde ao erro, isto é, à variabilidade de $Y$ não explicada pela relação linear. Cada variável (independente) é, no entanto, isolada e mantida constante enquanto as restantes variam sistematicamente, o que permite observar a sua influência na variável dependente.
Apesar de poderem ser utilizadas tantas variáveis quantas quisermos, nem todas acrescentam informação ao sistema analisado. 0 modelo de regressão múltipla, passo-a-passo, define, de entre o conjunto de variáveis, aquelas que vão ser introduzidas na equação de regressão, excluindo as que contêm informação redundante e as que não têm uma capacidade de explicação significativa.

O grau de ajuste do modelo tem como objetivo avaliar em que medida as variáveis integradas explicam as variações que se produzem na variável dependente. 0 mais utilizado é o coeficiente de determinação $R^{2}$, que indica a proporção de variância da variável dependente explicada pelas variáveis independentes introdu-

Quadro II

Variáveis dependentes e independentes utilizadas, a nível distrital

\begin{tabular}{|c|c|c|}
\hline & VARIÁVEIS DEPENDENTES & FONTE \\
\hline \multicolumn{3}{|c|}{ Incidência de incêndios florestais (1981-2010) } \\
\hline TO & Total de ocorrências & \multirow[t]{6}{*}{ Autoridade Florestal Nacional, AFN } \\
\hline DO & Densidade de ocorrências (10 km²) & \\
\hline ATA & Área total ardida (em hectares) & \\
\hline PAA & Percentagem de área ardida por distrito & \\
\hline AMO & Área média ardida por ocorrência (em hectares) & \\
\hline \multicolumn{2}{|r|}{ VARIÁVEIS INDEPENDENTES } & \\
\hline \multicolumn{3}{|c|}{ Características biofísicas } \\
\hline IRT & Indicador de rugosidade topográfica & Agência Portuguesa do Ambiente \\
\hline PMA & Precipitação média anual (em mm), 1971-2000 & \multirow{4}{*}{ Instituto de Meteorologia } \\
\hline TMA & Temperatura média anual $\left(\mathrm{em}^{\circ} \mathrm{C}\right), 1971-2000$ & \\
\hline TMM & Média anual da temperatura máxima $\left(\mathrm{em}^{\circ} \mathrm{C}\right), 1971-2000$ & \\
\hline NMS & Número de meses secos, 1971-2000 & \\
\hline \multicolumn{3}{|c|}{ Características sociodemográficas } \\
\hline TP & População total, 2001 & \multirow[t]{5}{*}{ Recenseamentos Gerais da População, INE } \\
\hline DP & Densidade de população, 2001 & \\
\hline VP & Variação da população, 1960-2001 (em \%) & \\
\hline PR & População rural, 2001 (em \%) & \\
\hline IE & Índice de envelhecimento, 2001 & \\
\hline \multicolumn{3}{|c|}{ Mudanças no uso e cobertura vegetal do solol Atividades económicas } \\
\hline AA & Área agrícola, em \%, 2006 & \multirow[t]{4}{*}{ CoRINE Land Cover } \\
\hline PAH & Pastagens e áreas agrícolas heterogéneas, em \%, 2006 & \\
\hline $\mathrm{AF}$ & Área de floresta, em \%, 2006 & \\
\hline Al & Área inculta, em \%, 2006 & \\
\hline VAA & Variação na área agrícola, em \%, 1951/56-2006 & \multirow[t]{7}{*}{ CORINE Land Cover vs SROA } \\
\hline VPAH & $\begin{array}{l}\text { Variação nas pastagens e áreas agrícolas heterogéneas, em \%, } \\
1951 / 56-2006\end{array}$ & \\
\hline VAF & Variação na área de floresta, em \%, 1951/56-2006 & \\
\hline VAl & Variação na área inculta, em \%, 1951/56-2006 & \\
\hline FD & Floresta dominante, 2006 & \\
\hline $\mathrm{FD}_{\mathrm{fl}}$ & Espécies folhosas, em \%, 2006 & \\
\hline $\mathrm{FD}_{\mathrm{rs}}$ & Espécies resinosas, em \%, 2006 & \\
\hline TGM & Total de gado miúdo, 1999 & \multirow[t]{3}{*}{ Recenseamentos Agrícolas, INE } \\
\hline DGM & Densidade de gado miúdo, 1999 & \\
\hline VGM & Variação no total de gado miúdo, em \%, 1955-1999 & \\
\hline \multicolumn{3}{|c|}{ Estrutura das explorações } \\
\hline $\mathrm{DE}$ & Dimensão média das explorações, 1999 & \\
\hline NP & № de parcelas por exploração, 1999 & \\
\hline DP & Dimensão media das parcelas, 1999 & \\
\hline
\end{tabular}


zidas no modelo. O coeficiente de determinação apresenta uma variação positiva entre 0 e 1 , podendo ter uma leitura percentual (\%). A validação do modelo de regressão realiza-se através da aplicação de provas ou contrastes de significado, constando entre os mais habituais os testes $\mathrm{T}$, associados a um nível de significância inferior a 0,05 ( $p$-value $<0,05)$. Estes testes são úteis para se decidir se certas variáveis independentes podem, ou não, ser eliminadas da equação de regressão.

\section{Resultados}

a) Número de ocorrências e área ardida: tendências e incidência regional

No decurso das últimas três décadas, mais de meio milhão de ignições foram registadas, tendo devastado uma área que se aproxima dos 3,3 milhões de hectares, o que, em termos relativos, representa mais de $1 / 3$ do território continental português. A evolução inter-anual do número de ocorrências e área ardida em Portugal continental mostra, nas últimas 3 décadas, uma tendência positiva, tanto no total de ocorrências como nas áreas ardidas (figura 1), apesar desta tendência apenas se revelar estatisticamente significativa para o número de ignições $\left(R^{2}=0,718\right.$ e $p$-value $\left.<0,000\right)$. Em média, nesta última década, assinalaram-se aproximadamente 26000 ocorrências/ano, enquanto nas décadas anteriores, de 90 e 80 , o número de ignições foi, respectivamente, de 24750 e 8200 . Os máximos anuais de ignições, cujo valor ultrapassou 30000 ocorrências, foram assinalados nos anos de 1995, 1998, 2000, 2005, 2007 e 2010.

No que se refere à área ardida, verifica-se que nesta última década (2001-2010) a média anual rondou 144000 ha, valor que foi $36 \%$ superior à década precedente (1991-2000), com uma média anual de 106000 ha. A década de 80 foi a que apresentou as menores áreas médias anuais, aproximadamente 83000 ha, menos $28 \%$, em relação à seguinte, e menos $74 \%$, se confrontada com a primeira década do novo milénio. 0 ano de 2003 foi, sem dúvida, o mais dramático, com mais de 400000 ha a serem percorridos pelas chamas, seguido de perto pelo de 2005, com uma área ardida a superior a 330000 ha.

Foi nos meses de Junho $( \pm 7 \%)$, Julho $( \pm 21 \%)$, Agosto $( \pm 30 \%)$ e Setembro (21\%) que ocorreram, aproximadamente, $80 \%$ das ignições anuais, enquanto que cerca de $50 \%$ da área ardida se concentrou no mês de Agosto.

A distribuição inter-regional dos valores médios anuais mostra que foi no distrito do Porto onde se assinalou o maior número de ocorrências, cerca de 4000, o que representa $1 / 4$ das ignições a nível nacional (Figura 2). Em contrapartida, nos distritos alentejanos, a média anual ronda, no período analisado, a centena de ocorrências. Relativamente à área ardida, o distrito da Guarda emerge como o mais flagelado pelas chamas, com um valor médio anual superior a 18 mil ha. Os distritos de Viseu, Castelo Branco, Vila Real, Coimbra e

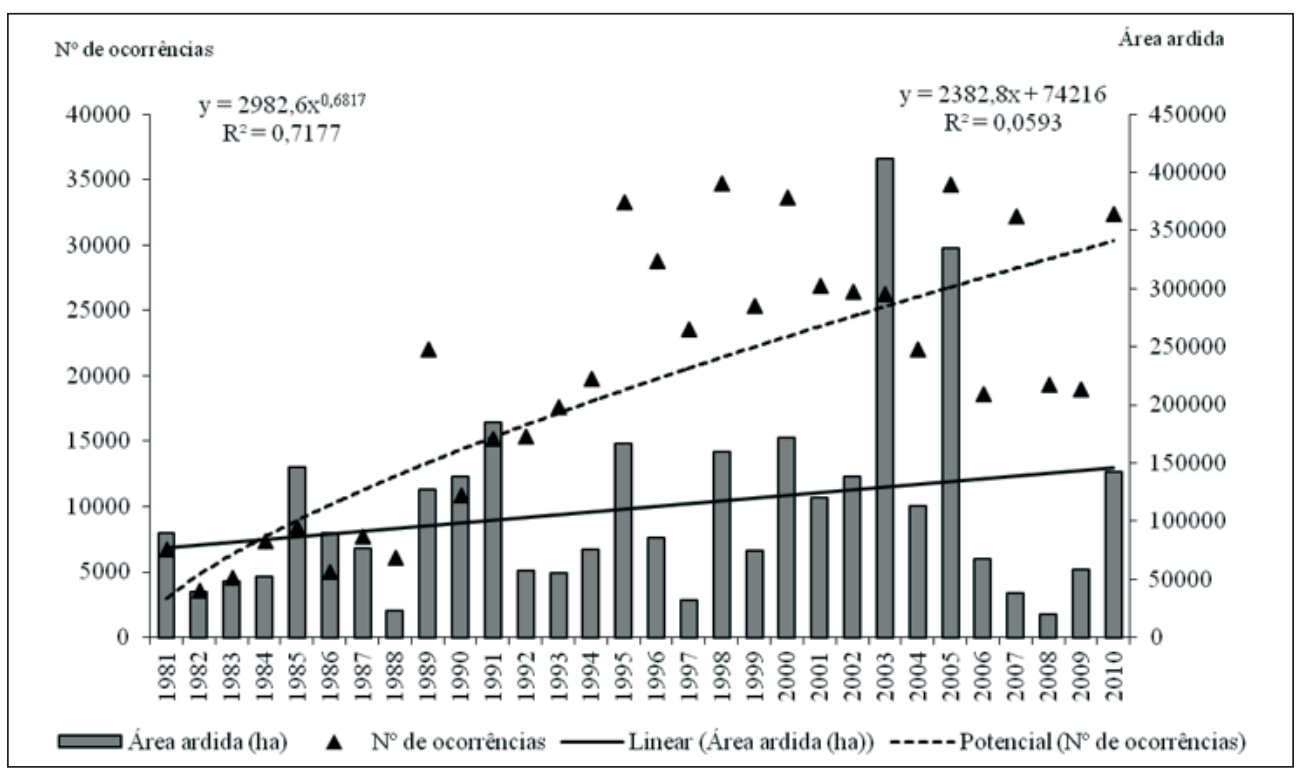

Figura 1

Evolução e tendências no número de ocorrências e área ardida, em Portugal continental (1981-2010). 


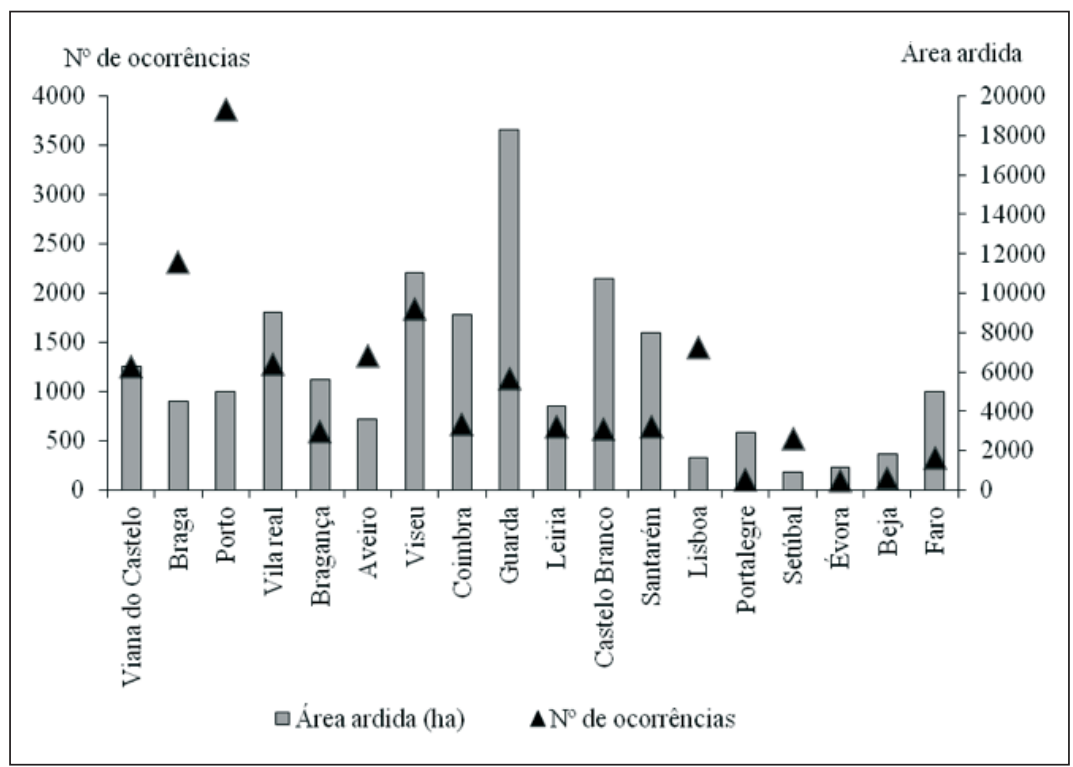

Figura 2

Número médio de ocorrências e área média ardida por distrito (1981-2010).

Santarém surgem na sequência, com uma média anual a oscilar entre 8000 e 11000 ha ardidos. Os distritos de Setúbal, Évora, Beja e Lisboa assinalam as menores áreas ardidas, inferiores a 2000 ha/ano.

A inter-relação da distribuição das ocorrências ou da área ardida com a área total do respetivo distrito, continua a destacar o do Porto (com 16 ocorrências $/ 10 \mathrm{~km}^{2} / \mathrm{ano}$ ) como sendo o mais suscetível à ignição de incêndios, seguido dos de Braga (com 8 ocorrên- cias $/ 10 \mathrm{~km}^{2} / \mathrm{ano}$ ) e de Viana do Castelo (com 6 ocorrências $/ 10 \mathrm{~km}^{2} /$ ano) (Figura 3). Por sua vez, quando se considera a percentagem média anual de área ardida, o distrito da Guarda permanece como o mais afetado pelas chamas (cerca de 3,5\%/ano), embora o de Viana do Castelo apresente um valor não muito distante deste (cerca de 3\%/ano). Os distritos de Évora, Beja e Setúbal destacam-se pela reduzida densidade de ocorrências e percentagem média anual de área ardida.

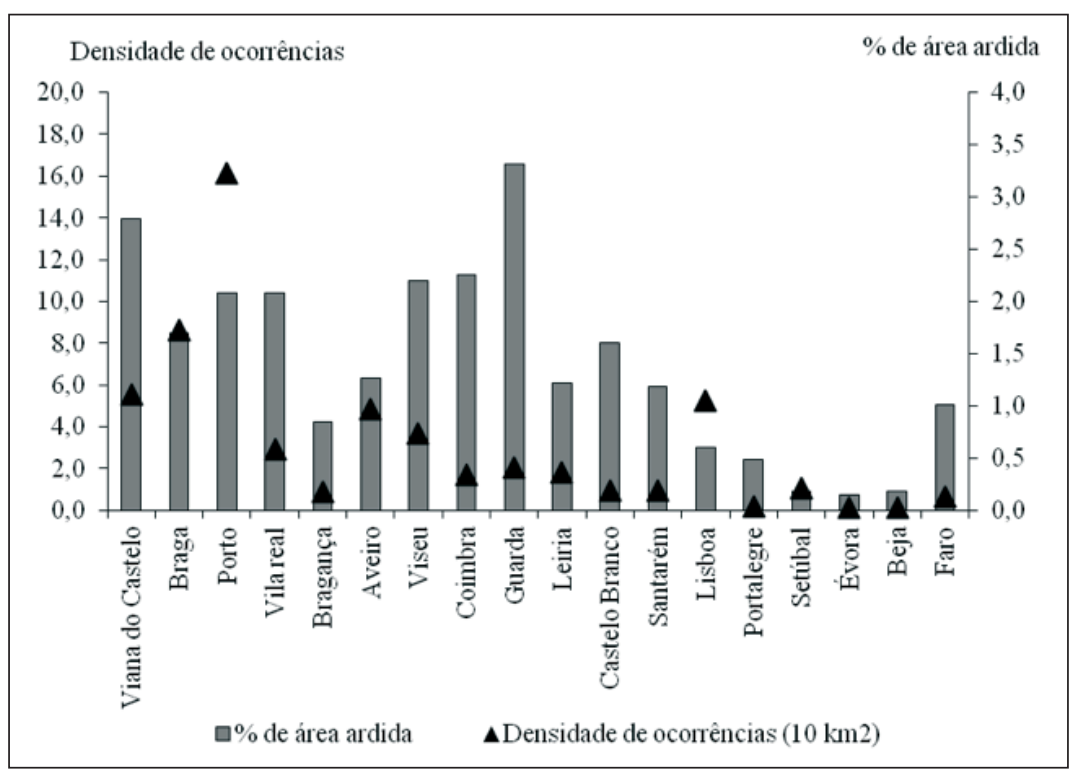

Figura 3

Densidade média anual de ocorrências (10km²) e percentagem média de área ardida, por distrito (1981-2010). 


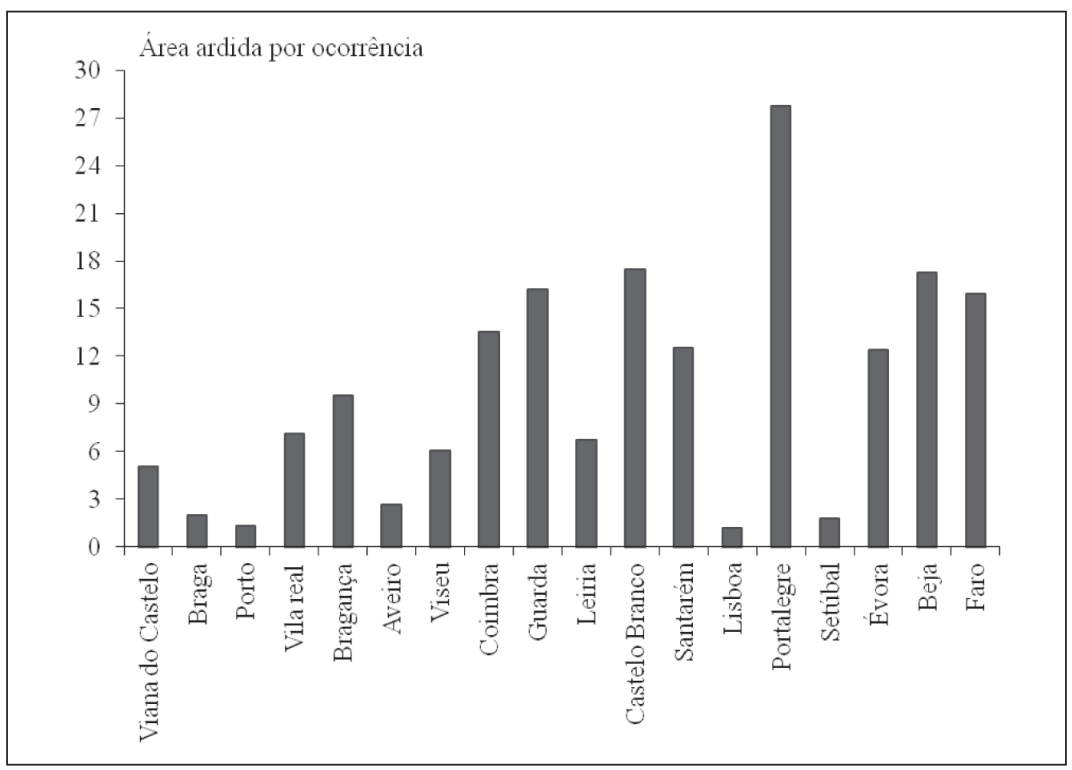

Figura 4

Área média ardida por ocorrência (1981-2010).

A relação entre o número de ocorrências e a área ardida em cada distrito, faz sobressair o de Portalegre, com cerca de 30ha incinerados por cada ignição, seguido pelos de Castelo Branco, Beja, Faro e Guarda. Em contrapartida, nos distritos do Porto, Lisboa, Braga e Setúbal a área média ardida por ignição não ultrapassou 3ha (Figura 4).

b) Número de ocorrências e área ardida: principais fatores responsáveis

A aplicação do coeficiente de correlação de Spearman, com o intuito de detetar correlações entre as variáveis relativas aos incêndios florestais, mostrou que, entre o número de ocorrências e a respetiva densidade, a associação é elevada ( $R s=0,953, p$-value: 0,000 ), assinalando-se o mesmo entre o total ardido e a percentagem de área ardida por distrito (Rs: 0,821; $\mathrm{p}$ value: 0,000 ).

Por outro lado, tanto o número de ignições como a sua densidade, não denotam, com o total de área ar- dida, uma correlação com significado estatístico (Rs: 0,370 ; $p$-value: 0,130 ; Rs: 0,240 ; $p$-value: 0,336 ), evidenciando comportamentos diferenciados em termos de distribuição regional e, por conseguinte, diferentes fatores expositivos.

Assim, com o objetivo de aclarar a dependência cumulativa das variáveis dependentes (relacionadas com os incêndios florestais) em relação às independentes (associadas aos fatores físicos, sociodemográficos, mudanças no uso e coberto vegetal do solo e estrutura das propriedades) aplicaram-se regressões múltiplas, cujos resultados se encontram sistematizados nos Quadros III a VI.

Dos resultados obtidos, a variável que melhor explica a distribuição da densidade de ocorrências a nível regional, devido à elevada capacidade de explicação da variância inter-distrital observada (cerca de 64\%), é a densidade populacional (Quadro III). No entanto, a aplicação da regressão múltipla fez emergir um segundo modelo, o qual associa uma outra variável, referente

Quadro III

Correlações, erro padrão estimado e equação da regressão múltipla para a densidade de ocorrências registadas nas últimas 3 décadas (1981-2010)

\begin{tabular}{|l|c|c|c|c|l|}
\hline & Modelo & $\mathrm{R}$ & $\begin{array}{c}\text { Variância } \\
\text { explicada }\end{array}$ & $\begin{array}{c}\text { Erro padrão } \\
\text { estimado }\end{array}$ & Equação da regressão múltipla \\
\hline $\begin{array}{l}\text { Densidade de } \\
\text { ocorrências }\end{array}$ & 1 & 0.802 & 64.3 & 7.602 & $\mathrm{DO}=2.616+0.42 \mathrm{DP}$ \\
\cline { 2 - 7 } & 2 & 0.925 & 85.5 & 4.997 & $\mathrm{DO}=-14.915+0.035 \mathrm{DP}+0.020 \mathrm{PMA}$ \\
\hline
\end{tabular}

Variável dependente: DO- Densidade de ocorrências $\left(\mathrm{km}^{2}\right)$ 1981-2010.

Modelo: 1- Variáveis explicativas integradas: (Constante), DP: Densidade populacional (2001);

2- Variáveis explicativas integradas no modelo: (Constante), DP: Densidade populacional (2001); PMA: Precipitação média anual. 
aos quantitativos médios anuais de precipitação (19712000), embora a sua quota-parte de explicação seja inferior à anterior variável, ao justificar apenas cerca de $20 \%$ da variabilidade observada na densidade de ignições. O facto das correlações, entre as variáveis dependente e independentes, assumirem um sinal positivo, tal significa que é nas áreas densamente povoadas e com maiores quantitativos anuais de precipitação que se assinala o maior número de ocorrências.

No que toca à área ardida, o modelo introduz apenas uma variável explicativa, a percentagem de área inculta (em 2006), a qual justifica per se 60\% da variação inter-regional observada (Quadro IV), ao passo que na explicação da percentagem ardida surgem três variáveis (Quadro V). A primeira, a determinante, justifica mais de $70 \%$ da variabilidade regional observada e refere-se ao indicador de rugosidade topográfica. A segunda, acrescenta cerca de $10 \%$ de capacidade preditiva ao modelo de regressão e relaciona-se com a área inculta. Por último, é introduzida a variação observada na área florestal, nestas últimas décadas, embora esta variável apenas acrescente um coeficiente de explicação de cerca de $6 \%$. As relações entre as variáveis independentes e a dependente são, nos dois primeiros casos, de sinal positivo, enquanto que, com a terceira, é de sinal negativo.

Relativamente à área média ardida por ocorrência, apenas se destaca uma variável, o índice de envelhecimento. A variância inter-distrital observada é explicada, em $73 \%$ dos casos, por esta variável, sendo o respetivo sinal de correlação positivo (Quadro VI).

\section{Discussão e conclusão}

Os resultados obtidos mostram uma tendência positiva, tanto do número de ocorrências como das áreas ardidas, em Portugal continental, nestes últimos 30 anos, apesar de apenas se revelar estaticamente significativa para a primeira das variáveis. Esta tendência é consistente com os resultados obtidos em outras áreas da região mediterrânea, em particular nas penínsulas

Quadro IV

Correlações, erro padrão estimado e equação da regressão múltipla para a área total ardida (em ha) registadas nas últimas 3 décadas (1981-2010)

\begin{tabular}{|l|c|c|c|c|c|}
\hline & Modelo & $\mathrm{R}$ & $\begin{array}{c}\text { Variância } \\
\text { explicada }\end{array}$ & $\begin{array}{c}\text { Erro padrão } \\
\text { estimado }\end{array}$ & Equação da regressão múltipla \\
\hline Área total ardida & 1 & 0.776 & 60.2 & 2910.685 & ATA= $-833.748+255.304 \mathrm{Al}$ \\
\hline
\end{tabular}

Variável dependente: ATA- Área total ardida, em ha, 1981-2010.

Modelo: 1- Variável explicativa integrada: (Constante), Al: Área inculta, em \%, (2006);

Quadro V

Correlações, erro padrão estimado e equação da regressão múltipla para a percentagem de área ardida/distrito nas últimas 3 décadas (1981-2010)

\begin{tabular}{|l|c|c|c|c|l|}
\hline & Modelo & $\mathrm{R}$ & $\begin{array}{c}\text { Variância } \\
\text { explicada }\end{array}$ & $\begin{array}{c}\text { Erro padrão } \\
\text { estimado }\end{array}$ & \multicolumn{1}{|c|}{ Equação da regressão múltipla } \\
\hline \multirow{3}{*}{$\%$ de área ardida } & 1 & 0.848 & 71.9 & 15.5187 & $\mathrm{PAA}=-7.577+32.487 \mathrm{IRT}$ \\
\cline { 2 - 7 } & 2 & 0.910 & 82.7 & 12.5705 & $\mathrm{PAA}=-15.214+21.000 \mathrm{IRT}+0.929 \mathrm{Al}$ \\
\cline { 2 - 7 } & 3 & 0.938 & 88.0 & 10.8467 & $\mathrm{PAA}=4.673+10.017 \mathrm{IRT}+1.176 \mathrm{AI}-0.185 \mathrm{VAF}$ \\
\hline
\end{tabular}

Variável dependente: PAA- Percentagem de área ardida, 1981-2010

Modelo: 1- Variável explicativa integrada: (Constante), IRT: Indicador de Rugosidade Topográfica

2- Variáveis explicativas integradas: (Constante), IRT: Índice de Rugosidade Topográfica, Al: Área inculta, 2006 (in \%)

3- Variáveis explicativas integradas: (Constante), IRT: Índice de Rugosidade Topográfica, Al: Área inculta, 2006 (in \%);

VAF: Variação na área de floresta, em \%, 1951/56-2006

Quadro VI

Correlação, erro padrão estimado e equação da regressão múltipla para a área média ardida/ocorrência nas últimas 3 décadas (1981-2010)

\begin{tabular}{|l|c|c|c|c|c|}
\hline & Modelo & $\mathrm{R}$ & $\begin{array}{c}\text { Variância } \\
\text { explicada }\end{array}$ & $\begin{array}{c}\text { Erro padrão } \\
\text { estimado }\end{array}$ & Equação da regressão múltipla \\
\hline Área ardida/ocorrência & 1 & 0.854 & 72.9 & 3.951 & $\mathrm{AMO}=-11,392+0.212 \mathrm{IE}$ \\
\hline
\end{tabular}

Variável dependente: AMO- Área media ardida por ocorrência, 1980-2009

Modelo: 1- Variável explicativa integrada: (Constante), IE: índice de envelhecimento (2001) 
Ibérica, itálica e grega (Pausas e ValeJo, 1999; JRC, 2005).

Com o intuito de explicar a crescente incidência de incêndios florestais, nestas últimas décadas, vários autores enfatizaram o efeito combinado de fatores socioeconómicos e mudanças no clima da região mediterrânea (VÉlez, 1993; Moreno e OeChel, 1995; Moreno et al. 1998; Romero-Calcerrada, 2008). Em Portugal, o êxodo da população rural para as áreas urbanas e para alguns dos países da Europa levou ao abandono dos usos tradicionais do território, assentes na trilogia agro-silvo-pastoril. Tradicionalmente, a maior parte da biomassa produzida nas florestas era recolhida pela população e utilizadas como fonte de combustível ou na cama dos animais. Por outro lado, nos pinhais recolhia-se a resina e a manta morta. A substituição da lenha por outras fontes de energia (gás, electricidade...) quebrou este balanço "natural" e levou à acumulação de grandes quantidades de biomassa combustível. Mais recentemente, as políticas agrícolas da União Europeia também promoveram o desmantelamento da estrutura produtiva e o abandono maciço das atividades agrícolas tradicionais.

A recolonização dos antigos campos de cultivo, com densas comunidades arbustivas e arbóreas, e sem qualquer tipo de gestão antrópica, favoreceram a continuidade horizontal e vertical dos combustíveis, o que faz com que, nas épocas mais críticas em termos de evapotranspiração, devido à simultaneidade de temperaturas elevadas e escassez de precipitação, a propagação das chamas seja facilitada, explicando, em parte, este incremento na magnitude e frequência dos incêndios (Moreno e Oechel, 1995; Moreno, 1998; Carvalho et al., 2002; MoReira et al., 2011). Por outro lado, a florestação dos espaços devolutos, focada em espécies altamente combustíveis, principalmente eucalipto (Eucalyptus globulus) e pinheiro bravo (Pinus pinaster), também terá favorecido a proliferação de incêndios florestas nestas últimas décadas (SHAKESBY et al., 1996).

Para além das alterações socioeconómicas, também as tendências positivas observadas nas temperaturas poderão ter contribuído para o incremento na ocorrência de incêndios (PIÑol et al., 1998; PAUSAS, 2004). Com efeito, a análise de informação meteorológica para a Península Ibérica confirma um incremento, tanto na temperatura mínima como nos seus valores máximos anuais (MIRANDa et al., 2002). Estas alterações podem ter favorecido a combustibilidade das plantas e, sobretudo, facilitar a propagação das chamas.

A análise à distribuição regional dos incêndios mostra que há distritos particularmente suscetiveis à sua deflagração (com particular destaque para os do Porto e Braga) e outros mais favoráveis à propagação das chamas (em especial os da Guarda, Viana do Castelo e Viseu). Os resultados obtidos denotam, assim, uma interessante dicotomia Norte/Centro vs Sul.

$\mathrm{Na}$ identificação dos principais fatores responsáveis pela ocorrência de incêndios florestais em Portugal continental, nestas últimas 3 décadas, destaca-se a presença humana como a principal causa pela desigual densidade e distribuição regional dos focos de ignição. Estes resultados concordam com os obtidos por vários autores, os quais também detetaram fortes correlações entre a densidade de ocorrências e a densidade de população nas áreas mediterrâneas da península Ibérica (Piñol e Terradas, 1996; Romero-Calcerrada et al., 2008; Martínez et al., 2009; Badia et al., 2011). De facto, os seres humanos são considerados a causa primária dos incêndios florestais em todo o mundo (PYNE, 1982), pelo que o aumento da população se traduz num incremento do risco potencial de deflagração de incêndios.

A distribuição regional das áreas ardidas resultou da sinergia entre fatores físico-geográficos (em particular da topografia, influenciando esta, por sua vez, outras variáveis como a temperatura e a precipitação) e mudanças sócio-económicas, com reflexo ao nível do uso e cobertura vegetal do solo. Com efeito, as maiores áreas ardidas ocorreram nas regiões com topografia mais acidentada e clima húmido e sub-húmido (associadas a menores temperaturas e maiores quantitativos anuais de precipitação) o qual permite o desenvolvimento de maiores quantidades de biomassa, em especial ao nível dos estratos herbáceos e arbustivos, por se regenerarem mais rapidamente.

Por outro lado, o intenso êxodo rural, com o consequente abandono de vastas áreas agrícolas e incremento das áreas denominadas de incultas, promoveram importantes transformações na paisagem, sobretudo ao nível da regeneração do coberto vegetal natural. $\mathrm{O}$ uso milenar do fogo como estratégia de controlo do coberto vegetal continua a ser utilizado, sobretudo nas regiões onde os estratos herbáceo e arbustivo se desenvolvem com maior rapidez e a pressão agro-pastoril ainda permanece.

A tendência observada, tanto no número de ocorrências como na área ardida, mostra que as sucessivas políticas/medidas implementadas com o objetivo de reduzir o número de ignições e de áreas percorridas pelas chamas não têm produzido os efeitos desejáveis em Portugal continental. Torna-se, neste contexto, urgente delinear uma estratégia nacional concertada e investir fortemente nas áreas da prevenção. 


\section{Referências Bibliográficas}

Almeida, A. C.; Nunes, A. e Figueiredo, A. (2009) - Mudanças no uso e cobertura vegetal no Interior Centro e Norte de Portugal. Imprensa da Universidade de Coimbra, 99 p.

Badia, A.; Serra, P. e Modugno, S. (2011) - "Identifying dynamics of fire ignition probabilities in two representative Mediterranean Wildland Urban Interface areas". Applied Geography, 31, pp. 930-940.

Camia, A. e Amatulli, G. (2009) - "Weather Factors and Fire Danger in the Mediterranean". In: Chuvieco, E. (ed.) Earth Observation of Wildland Fires in Mediterranean Ecosystems. Springer-Verlag, Berlin, pp. 71-82.

Carmo, M.; Moreira, F.; Casimiro, P. e Vaz, P. (2011) - "Land use and topography influences on wildfire occurrence in northern Portugal". Landscape and Urban Planning, 100, pp. 169. 176.

Carvalho, T. M.; Coelho, C. O. A.; Ferreira, A. J. D. e Charlton, C. A. (2002) - "Land degradation processes in Portugal: farmers ' perceptions of the application of European agroforestry programmes". Land Degradation and Development, 13, pp. 177-188.

Carvalho, A.; Flannigan, M. D.; Logan, K.; Miranda, A. I. e Borrego, C. (2008) - "Fire activity in Portugal and its relationship to weather and the Canadian Fire Weather Index System”. International Journal of Wildland Fire, 17, pp. 328-338.

CoRINE Land Cover (2006) - Mapa CORINE Land Cover (ocupação do solo) de 2006 para Portugal Continental. Agência Portuguesa para o Ambiente (acedido em 15/10/2011: http://sniamb.apambiente.pt/clc/frm/).

Costa, L.; Badeck, F. e Thonicke, K. (2007) - "Sensitivity of Portuguese forest fires to land use and climate factors". Wildfire Congress, Seville, Spain (acedido em 10/07/2011: http://www.fire.unifreiburg.de/ sevilla2007/contributions/doc/cd/SESIONES_ TEMATICAS/ST1/Costa_et_al_GERMANY_PT.pdf).

JRC (2005) - Forest Fires in Europe 2004. Joint Research Center S.P.l.05.147 EN, European Communities.

KunKEL, K. K. (2001) - "Surface energy budget and fuel moisture". In:Johnson E. A. e MiYanishi, K. (Eds) Forest Fires Behaviour and Ecological Effects. Academic Press: San Diego, CA, pp. 303-350.

Leite, F. F.; Gonçalves, A. B. e Vieira, A. (2011) - "The recurrence interval of forest fires in Cabeço da Vaca (Cabreira Mountain-northwest of Portugal)". Environmental Research, 111, pp. 215-221.

Lourenço, L. (1988) - "Tipos de tempo correspondentes aos grandes incêndios florestais ocorridos em 1986 no Centro de Portugal”. Finisterra, 23, Lisboa, pp. 251-270.
LOURENÇO, L. (1991) - "Uma fórmula expedita para determinar o índice meteorológico de eclosão de fogos florestais em Portugal Continental”. Cadernos Científicos de Incêndios Florestais, Coimbra, Portugal.

Lourenço, L. e Gonçalves, A. B. (1990) - "As situações meteorológicas e a eclosão-propagação dos grandes incêndios florestais registados durante 1989 no Centro de Portugal”. In: II Congresso Florestal Nacional. Porto, Portugal, pp. 755-763.

Martínez, J.; Vega-García, C. e Chuvieco, E. (2009) - "Humancaused wildfire risk rating for prevention planning in Spain”. Journal of Environmental Management, 90, pp. 1241-1252.

Mermoz, M.; Kitzberger, T. e Veblen, T. T. (2005) - "Landscape influences on occurrence and spread of wildfires in Patagonian forests and shrublands". Ecology, 86, pp. 2705-2715.

Moreira, F.; Viedma, O.; Arianoutsou, M. ; Curt, T.; Koutsias, N.; Rigolot, E.; Barbati, A.; Corona, P.; Vaz, P. ; Xanthopoulos, G. ; MouILlot, F. e BILGILI, E. (2011) - "Landscape - wildfire interactions in southern Europe: Implications for landscape Management". Journal of Environmental Management,92, pp. 2389-2402.

Moreno, J. M. e Oechel, W. C. (1995) - Global change and Mediterranean-type ecosystems. Springer, New York.

Moreno, J. M. (ED) (1998) - Large Fires. Backhuys Publishers, Leiden, The Netherlands.

Pausas, J. e Vallejo, R. (1999) - "The role of fire in European Mediterranean ecosystems". In: Chuvieco, E. (Ed.) Remote Sensing of Large Wildfires in the European Mediterranean Basin. Springer-Verlag, Berlin, pp. 3-16.

Pereira, A. R. e Ramos, C. (1999) - Avaliação da diversidade biofísica do território (Base administrativa). Edições colibri e Associação Portuguesa de Geógrafos, Lisboa, pp. 47-55.

Pereira, M. G.; Trigo, R. M.; Da Câmara, C. C.; Pereira, J. C. e Leite, S. M. (2005) "Synoptic patterns associated with large summer forest fires in Portugal”. Agricultural and Forest Meteorology, 129, pp. 11-25.

Piñol, J.; Terradas, J. e Lloret, F. (1998) - "Climatic warming hazard, and wildfire occurrence in coastal eastern Spain”. Climate Change, 38, pp.345-357.

PYNE, S. J. (1982) - Fire in America: a cultural history of wildland and rural fire. Princeton. University Press, New Jersey, USA.

Pyne, S. J.; Andrews, P. L. e LaVen, R. D. (Eds) (1996) - Introduction to Wildland Fire. Wiley, NewYork.

Rebelo, F. (1980) - "Condições de tempo favoráveis à ocorrência de incêndios florestais. Análise dos dados referentes a Julho e Agosto de 1975 na área de Coimbra”. Biblos, 56, pp. 653-673. 
Romero-Calcerrada, R.; Novillo, C. J.; Millington, J.D.A. e GomezJIMENEZ, I. (2008) - "GIS analysis of spatial patterns of human-caused wildfire ignition risk in the SW of Madrid (Central Spain)". Landscape Ecology, 23, pp. 341-354

Rothermel, R. (1983) - How to Predict the Spread and Intensity of Forest and Range Fires USDA. Forest Service, Intermountain Forest and Range Experiment Station, General Technical Report INT-143, Ogden, UT.

Skinner, W.; Stocks, B.; MarTell, D.; Bonsal, B. e Shabbar, A. (1999) - "The association between circulation anomalies in the mid-troposphere and area burned by wildland fire in Canada". Theoretical and Applied Climatology, 63, pp. 89-105.

SROA (Serviço de Reconhecimento e Ordenamento Agrário) (1970) - A utilização do solo em Portugal Continental. Lisboa, Secretaria de Estado da Agricultura, Serviço de Reconhecimento e Ordenamento Agrário.
Viegas, D. X.; Viegas, M. T. e Ferreira, A. D. (1992) - "Moisture content of fine forest fuels and fire occurrence in Central Portugal". International Journal of Wildland Fire, 2, pp. 69-86.

VIEGAS, D. X. e VIEGAS, M. T (1994) - "A relationship between rainfall and burned area for Portugal". International Journal of Wildland Fire, 4(1), pp. 11-16.

VIEGAS, D. X.; PIÑoL, J.; VIEGAS, M. T. e OGAYA, R. (2001) - "Estimating live fine fuels moisture content using meteorologically based indices". International Journal of Wildland Fire, 10 , pp. 223-240.

VIEGAS, D. X.; ReIs, R. M.; CRUZ, M. G.; VIEGAS, M. T. (2004) - "Calibração do sistema canadiano de perigo de incêndio para aplicação em Portugal”. Silva Lusitana, 12(1), pp. 77-93.

Westerling, A. (2008) - "Climate and Wildfire in the Western United States". (Acedido em 7/06/2011: http:// meteora.ucsd.edu/cap/pdffiles/westerling_fire08.pdf). 